\title{
ORBIS LITTERARUM
}

\section{РЕЦЕНЗИЯ}

УДК 008(049.32)

ББК 71

DOI 10.25281/2072-3156-2019-16-2-208-213

\section{Т.И. ЕРОХИНА}

\section{ПРИКЛАДНАЯ КУЛЬТУРОЛОГИЯ ОТ А ДО Я: КОНЦЕПТЫ, СФЕРЫ, ПРАКТИКА}

\section{Татьяна Иосифовна Ерохина,}

Ярославский государственный театральный институт, проректор по учебной работе

Депутатская ул., д. 15/43,

Ярославль, 150000, Россия

Ярославский государственный педагогический университет им. К.Д. Ушинского,

кафедра культурологии,

заведующая

Республиканская ул., д. 108/1,

Ярославль, 150000 , Россия

доктор культурологии, просессор

ORCID 0000-0002-8328-2546; SPIN 2148-5497

E-mail: TIErokhina@yandex.ru

Реферат. Статья представляет собой рецензию на Энцииклопедию «Прикладная культурология» под ред. профессора И.М. Быховской (Москва, Изд-во «Согласие», 2019), посвященную концептуализации и систематизации научных исследований в сфере прикладной культурологии, представленных в проблемно-тематических блоках, рассматривающих разные уровни и сферы этой области знания: от теоретико-методологических контекстов развития прикладных исследований, осмысления научного инструментария, культурологических кониептов и сочиокультурного пространства как предметного поля - к социальным практикам в культурологическом измерении. В рецензии получили отражение структурные и содержательные параметры издания, особенности теоретического и эмпирического материала, жанровая специфика и символическая составляющая. Дана оценка энщиклопедическому изданию, раскрыта его уникальность и научная значимость. Оно рассматривается как весомый вклад в современное культурологическое знание, его пропаганду и расширение сфер использования. Выход в свет Энциклопедии представлен в контексте уже сформировавшихся тенденций осмысления и 
изучения научного направления, а также в аспекте нового этапа развития культурологического знания, утверждающего себя не только в свете теоретико-методологических и историко-культурных исследований, но и в сфере сойопространства и практик. Издание рассматривается как многоаспектный и многогранный труд, представленный внушительным авторским коллективом из разных городов России, и при этом как иелостное, кониептуально структурированное издание, выгодно отличаюшееся от многих изданий справочного характера. Направленный на фундированное осмысление культурных прочессов и явлений, на привлечение внимания специиалистов-гуманитариев, преподавателей и студентов высших учебных заведений к проблемам прикладного использования культурологических знаний, данный проект представляет собой комплексное энииклопедическое издание, совмешающее в себе теоретико-методологическую базу со справочным материалом и авторским подходом.

Ключевые слова: теория и история культуры, прикладная культурология, концептуальность, социокультурные практики, методология, многовекторность, сферы культуры.

Для цитирования: Ерохина Т.И. Прикладная культурология от А до Я: концепты, сферы, практика // Обсерватория культуры. 2019. T. 16, № 2. C. 208-213. DOI: $10.25281 / 2072-$ 3156-2019-16-2-208-213.

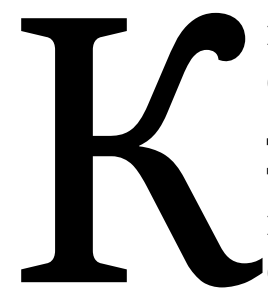

нижная полка исследователей социокультурных проблем, деятельности и действий, как теоретиков, так и практиков, в большей или меньшей мере связанных с культурной составляющей социального мира, пополнилась новым, масштабным, актуальным и научно значимым изданием - Энциклопедией «Прикладная культурология» под редакцией профессора И.М. Быховской (Москва, Изд-во «Согласие», 2019. - 846 с.). Актуальность этого весьма солидного тома не вызывает сомнения в силу ряда обстоятельств. Во-первых, изданий, обобщенно представляющих особый раздел культурологии - прикладную культуроло- гию, в отечественной науке крайне мало, на что справедливо указывает в концепт-преамбуле к Энциклопедии ее редактор, много лет занимающийся проблемами культурологических исследований в прикладных аспектах. Во-вторых, профиль представленного коллективного исследования относится к тем редким на сегодняшний день моделям издания, которые чрезвычайно востребованы, поскольку позволяют найти ответы (или, по крайней мере, необходимые ориентиры для их поиска) на вопросы, касающиеся актуальных социальных проблем, трендов социокультурного развития, конкретных форм практической деятельности в их культурологически значимой интерпретации. Подчеркнем и то немаловажное обстоятельство, что издания такого рода дают культурологам определенную систему аргументов при отстаивании нужности и важности своей науки «здесь и сейчас» в условиях, когда во многих учебных заведениях культурология не рассматривается как необходимая и востребованная научная дисциплина. Представленный в Энциклопедии анализ самых разных социальных практик (инженерных, педагогических, досуговых, оздоровительных и т. д.) с точки зрения их культурных смыслов и социального контента, а также востребованности в различных сферах деятельности - это важный аспект для укрепления позиций культурологии как практически важного знания для профессионалов в самых разных областях жизни социума.

Нельзя не отметить масштабность (более 60 человек) и научный профессионализм коллектива авторов издания, в котором представлены имена многих известных исследователей Москвы, Санкт-Петербурга, Екатеринбурга, Смоленска, Саратова и др. (О.И. Горяинова, Ю.А. Грибер, О.А. Жукова, Н.Б. Кириллова, А.В. Костина, С.В. Лурье, Э.В. Махрова, Л.В. Никифорова, Э.А. Орлова, К.Э. Разлогов, В.М. Розин, О.О. Савельева, А.Я. Флиер, А.Ю. Шеманов и др.). Прекрасной и научно весомой рекомендацией для издания, несомненно, являются имена рецензентов, профессионалов высокого уровня, давших Энциклопедии «зеленый свет»: профессоров Е.В. Дукова, Т.Ф. Кузнецовой, И.В. Малыгиной.

Энциклопедия «Прикладная культурология» - новинка во многих смыслах этого слова, 
однако продолжающая ясно обозначившиеся тенденции в развитии такого рода «сводных» изданий в последнее десятилетие. Прежде всего обратим внимание на жанр издания, который можно обозначить как «энциклопедическое исследование». Он выстроился в ходе подготовки и публикации ряда книг коллективом Российского института культурологии с 2005 по 2012 г., как, например, энциклопедический том «Теоретическая культурология» под редакцией О.К. Румянцева и А.Ю. Шеманова (Москва, Академический проект, 2005 г. и др.). Энциклопедическое исследование - это концептуально выстраиваемое издание по принципу «два в одном», а в нашем случае - соединяющее гораздо больше составляющих. Это сочетание теоретико-монографического (коллективного, как правило) исследования с внушительной методологической базой традиционного справочного издания, но не лишенное авторского взгляда на концепты, идеи и направления развития прикладной культурологии. Именно такая ключевая идея весьма удачно выражена во вступительной статье редактора и в основной части публикации. Такая интеллектуальная детерриторизация ${ }^{1}$ перекликается с общим построением всего культурологического знания в целом, стирающего предметную демаркацию и проблемную вертикаль построения: знания живого, движущегося, ситуационно обозначающего свои теоретические вертикали и предметные горизонтали. Интересно, что этот методологический подход и редакторский замысел открывается внимательному читателю, начиная уже с художественного оформления обложки, где, как нам представляется, подчеркнуты две смысловые доминанты: с одной стороны, справочная направленность издания (через выделение последних букв в названии - «прикладная»), а с другой - представленная мозаичным орнаментом на обложке сложносоставность, многомерность коллективного исследования, ориентированного на монографическое единство в его тематическом многообразии (что, собственно, характерно и для культурологии в целом). А если добавить сюда еще «мудрость» (сова), вооружившуюся рабочим ин-

${ }^{1}$ Детерриторизация - постмодернистская концепция метафорического «ухода с оседлой территории». струментом, то независимо от того, было ли такое оформление замыслом редакторов или это точно ухваченная художником (Е.В. Федорова) идея, в любом случае внешняя символика, представленная на обложке, обращает на себя внимание, особенно когда речь идет об издании в области культурологии - науки, далеко не чуждой вопросов семиотики, символики и символизации.

Но, конечно, существенно более важным проявлением основной идеи является структура и содержание тома - не вполне традиционные для «классического» типа энциклопедий. Логика построения материала выглядит весьма продуманной и обоснованной и воспроизводит то движение мысли, которое (в соответствии с исходной концепцией тома) характеризует особенности работы в сфере прикладной культурологии. С одной стороны, это - движение от теоретико-методологического осмысления проблемной ситуации, предметной зоны ее пребывания к выработке модели действия, обеспечивающей нахождение последующей практической технологии решения конкретных задач по преодолению возникшей проблемы. С другой - сами практические действия (а в пределе - сумма практик), направленные на реализацию того или иного конкретного проекта, рассматриваются как база для последующего, на новом витке, теоретического осмысления, позволяющего воспринять, проанализировать новый запрос и предложить возможные ответы на него. Следует отметить, что данный формат - это и есть концепция прикладной культурологии И.М. Быховской, которая изложена в ее прежних многочисленных трудах по данной проблеме [1; 2], а также результат работы коллектива авторов, развивающих и обогащающих идеи прикладной культурологии во всей их многовекторности, как это предложено и в ряде предшествующих публикаций [3], и в данном энциклопедическом томе. Концепция прикладной культурологии, представленная в нем и подытоживающая в каком-то смысле большой этап исследований в этой области, вполне органично вписана в сложившуюся в отечественной гуманитаристике модель культурологического знания. Не проводя прямых аналогий, можно все же сказать, что, как некогда в области социологии ученые занима- 
лись выработкой оснований и критериев для «теории среднего уровня» (то есть, по сути, искали методологически продуктивный синтез теории и практики), так и сегодня в области культурологии решение той же проблемы продолжает занимать свое важное место в наборе методологически важных вопросов - какова должна быть модель практически ориентированного культурологического знания.

В той модели, которая была ранее обоснована И.М. Быховской и сейчас взята за ориентир при формировании рассматриваемого издания, специфика прикладной науки (при ее, например, сопоставлении с фундаментальной) заключалась в том, что она представляла собой синтез теоретической и технологической составляющих. И здесь хотелось бы высказать некоторые возражения, прежде всего касающиеся того, что (как это утверждает во вводной статье редактор Энциклопедии) теоретический раздел культурологии выстроен, тогда как прикладной нуждается еще в более глубокой проработке и «достраивании». К сожалению, теоретические смыслы исследовательской работы в области культурологии сегодня во многом девальвированы, вкус к исследовательской деятельности в этой области заметно ослабевает, но зато, вместе с затасканным и лишенным всякого значения словом «креативность», растет интерес к разным формам «культурных практик», которые иногда оборачиваются просто кустарной деятельностью в области культурологии. И на этом фоне становится особенно актуальным и чрезвычайно значимым основной посыл концепции, лежащей в основании рассматриваемого издания, - это пусть и прикладная, но прежде всего наука. В этом посыле содержатся своевременное напоминание и социальная акцентировка: проектная, управленческая и другие формы деятельности должны базироваться на научных разработках, а не определяться выученными стереотипами отдельных форм практик, применение которых нередко утверждается как тождественное понятию «прикладная наука». Такой ориентир дает возможность отделить действительно практически ориентированную науку от квази- и псевдонауки.

Еще один очень важный аспект представленной модели прикладной культурологии как особого сегмента этой науки связан с напоминанием, что предметом ее являются культурные смыслы, создающие во времени культурную детерминацию, а в пространстве - поле диалога (полилога). Об этом сейчас напоминать крайне важно, поскольку не только у начинающих исследователей, но и у практикующих управленцев нередко перепутаны смыслы культурологического знания и объекта его приложения. И на новом витке мы сталкиваемся с проблемой, когда «культурологическое» касается только библиотек, музеев, театров. И хотя в перечисленных объектах культурного управления культурологическая деятельность находит вполне достойные формы реализации, выливаясь в эффективные современные проекты, программы, однако культурологическая деятельность ими далеко не исчерпывается. Необходимый поворот $\kappa$ культурному осмыслению самых разных видов и уровней социальных практик, масштабно представленный и реализованный в рассматриваемой Энциклопедии, и основанная на нем трактовка культурологического практического знания представляется методологически обоснованной, четко прописанной и соответствующей современным ориентирам познавательной деятельности.

Структура книги, отметим вновь, образно может быть представлена в форме мозаичного панно, которое выкладывается вокруг центральной, доминантной идеи исследования, то есть строится по принципу «единство в многообразии». «Прикладной вектор культурологии», как он обозначен редактором вступительной статьи, по сути, содержит в себе несколько разнонаправленных векторов исследования: исторический, морфологический, методологический, прикладной в узком смысле слова. Отсюда и структура построения материала: соблюдение принципа теоретической иерархичности, просматривающегося в четырех разделах («Теоретико-методологические контексты развития прикладных исследований» - «Инструментарий прикладной культурологии»; «Культурологические концепты, значимые для практико-ориентированного анализа» - «Социокультурное пространство: предметные поля прикладной культурологии»), и завершение этой логической 
архитектоники разделом «Социокультурные практики». Каждая статья внутри разделов, в большей или меньшей степени, воспроизводит общую концептуальную композицию, что, по-видимому, и явилось принципиальным ориентиром для достижения достаточного уровня единства издания при всем многообразии тематических и проблемных зон, представленных к рассмотрению. А проблематика, действительно, впечатляет масштабностью охвата и соотнесенностью со многими практическими социальными «зонами напряжения» и «точками роста» в современном мире. В поле зрения авторов более чем 150 статей. Они вошли в Энциклопедию в соответствии с общей логикой тома: столь актуальные процессы и феномены современного мира, как визуализация и аккультурация; социокультурные «болезни» и интеркультурализм; актуализация культурного наследия и проблема культурных ландшафтов; культурный сценарий и культурные стереотипы; «культура бедности» и «культура богатства»; научная культура и интеграция средствами культуры; вопросы инкультурации современных миллениалов и культура здоровья в современном обществе и многое другое.

Немаловажное значение для интересующихся формированием и использованием практико-ориентированного знания культурологического профиля имеет раздел, посвященный инструментарию данного сегмента знания, где представлены статьи о количественных методах в исследованиях культуры и о группе так называемых качественных методов; о диагностике проблемных ситуаций в социокультурном контексте и кросс-культурном анализе; о социокультурной экспертизе и оценке социальной эффективности программ и проектов в области культуры; о многих других инструментах, необходимых для прикладного изучения феноменов и процессов в современном культурном пространстве.

Одним из несомненных достоинств рассматриваемого издания является справочно-библиографическое сопровождение всех статей, позволяющее специалистам и интересующимся существенно расширить знания по тому или иному вопросу, нашедшему отражение в энциклопедической статье, весьма ограниченной по объему в силу своего жанра. Обращает на себя внимание и то, что в пристатейных списках литературы нашли отражение как соответствующие отечественные публикации последних лет, так и подборка актуальных иноязычных изданий по рассматриваемой проблеме. В этом смысле энциклопедия «Прикладная культурология» может быть хорошим информационным источником для читателей, включенных в образовательный процесс: преподавателей, студентов, аспирантов.

Конечно, как всякое издание такого масштаба, рассматриваемый том не лишен определенных недостатков - так, например, нельзя не заметить, что при всей обширности рассматриваемой тематики в ней есть некоторые лакуны, в частности, хотелось бы видеть более широкую представленность того, что связано с экономической культурой (хотя есть одна статья из этой области - «Экономика культуры»). При наличии именного указателя в издании отсутствует указатель предметный - хотя, возможно, при столь развернутой тематической структуре большой необходимости в нем и нет. По мере использования данного издания можно предположить, что возникнут и еще какието замечания и пожелания к редактору Энциклопедии или к отдельным авторам.

Сегодня можно с полной уверенностью говорить о том, что рассматриваемая книга - это важный итог и ориентир, база и вектор, экспертиза и указатель сложившихся и формирующихся направлений в прикладной культурологии. Важно, чтобы это солидное издание сыграло еще и роль катализатора дальнейшего развития социально важного и очень актуального раздела культурологического знания. Но уже сегодня можно с уверенностью утверждать, что Энциклопедия стала не только масштабной и значимой научной работой в области культурологии, но и свидетельствует о действительно прикладном значении культурологии - науки, предметом изучения которой является культура в ее концептах, пространствах и практиках.

\section{Список источников}

1. Быховская И.М. Культурология: знание - в действие // Александрова Е.Я., Быховская И.М. Культурологические опыты. Москва : РИК, 1996. С. $42-54$. 
2. Быховская И.М. Прикладная культурология: потенциальное vs актуальное // Обсерватория культуры. 2011, № 4. С. 4-12.
3. Культурология: Фундаментальные основания прикладных исследований / под ред. И.М. Быховской. Москва : Смысл, 2010. 640 с.

\section{Applied Cultural Studies from A to Z: Concepts, Spheres, Practice}

\section{Tatiana I. Erokhina}

Yaroslavl State Theater Institute, 15/43, Deputatskaya Str., Yaroslavl, 150000, Russia

Yaroslavl State Pedagogical University named after K.D. Ushinsky, 108/1, Respublikanskaya Str., Yaroslavl, 150000, Russia

ORCID 0000-0002-8328-2546; SPIN 2148-5497

E-mail: TIErokhina@yandex.ru

\begin{abstract}
The article represents a review of "Applied Cultural Studies" Encyclopedia edited by Doctor of Philosophy, Professor I.M. Bykhovskaya (Moscow, "Soglasie" Publishing House, 2019) and dedicated to conceptualization and systematization of research studies in the sphere of applied cultural studies. They are represented in problem-subject units, considering different levels and spheres of this field of knowledge: from theoretical and methodological contexts of development of applied studies, comprehension of scientific tools, concepts of cultural studies and sociocultural space as a subject field, to social practices in cultural studies dimension. The review reflects the structural and substantive parameters of the publication, features of theoretical and empiric material, genre specificity and symbolic constituent. It gives appraisal of the encyclopedic publication and reveals its unicity and scientific significance. The publication is regarded as strong contribution in contemporary cultural knowledge, its outreach and widening spheres of applying. The Encyclopedia is presented in the context of already formed tendencies of comprehension and research of the scientific field as well as in terms of a new stage of development of cultural know-
\end{abstract}

ledge confirming itself not only in the light of theoretical-methodological and historical-cultural research but in the area of social space and practices. The publication is considered as a multidimensional and multifaceted work represented by magnifical writing staff from different Russian cities. Herewith, it is an integral, conceptually structured book, which compares favorably with many other reference publications. Being focused on funded comprehension of cultural processes and events, on attracting the attention of humanities scholars, lecturers and university students to the problems of applied use of cultural knowledge, this project represents a complex encyclopedic publication integrating theoretical-methodological base with reference material and the author's approach.

Key words: theory and history of culture, applied cultural studies, conceptual importance, sociocultural practices, methodology, multivectorness, spheres of culture.

Citation: Erokhina T.I. Applied Cultural Studies from A to Z: Concepts, Spheres, Practice, Observatory of Culture, 2019, vol. 16, no. 2, pp. 208-213. DOI: 10.25281/2072-3156-2019-16-2-208-213.

\section{References}

1. Bykhovskaya I.M. Cultural Studies: Knowledge into Action, Aleksandrova E.Ya., Bykhovskaya I.M. Kul'turologicheskie opyty [Aleksandrova E.Ya., Bykhovskaya I.M. Cultural Experiences]. Moscow, RIK Publ., 1996, pp. 42-54 (in Russ.).

2. Bykhovskaya I.M. Applied Cultural Studies: Potential vs Current, Observatoriya kul'tury [Observatory of Culture], 2011, no. 4, pp. 4-12 (in Russ.).

3. Bykhovskaya I.M. (ed.) Kul'turologiya: Fundamental'nye osnovaniya prikladnykh issledovanii [Cultural Studies: Fundamental Bases of Applied Research]. Moscow, Smysl Publ., 2010, 640 p. 